\title{
Users' Reactions Captured by Means of an EEG Headset on Viewing the Presentation of Sustainable Designs Using Verbal Narrative
}

\author{
Marta Royo, Vicente Chulvi and Elena Mulet \\ Department of Mechanical Engineering and Construction, Universitat Jaume I, \\ Castello de la Plana, Spain, and \\ Julia Galán \\ Department of Industrial Systems and Design Engineering, Universitat Jaume I,
}

Marta Royo is the corresponding author and can be contacted at: royo@uji.es

\begin{abstract}
The aim of this paper is to determine whether consumers accept new arguments for choosing a product that adapts to future needs. It is also seeks to investigate whether the design of products and their ensuing advertising and promotion through a sustainable approach by means of verbal narrative ads can generate a more positive emotional response in the future users of the product than with the application of visual narrative ads.

To this end, an experiment was conducted consisting in consumers, with and without experience with the product, watching a promotional video based on verbal narrative, created using the new usage scenarios approach, in which the advantages of a sustainable product are shown. The neuronal response of the possible users was then measured by means of the EEG headset. In order to be able to establish a comparison, the same response was also measured in the same consumers when they viewed a commercial video based on visual narrative about a product with similar characteristics.

The results show, among other conclusions, that viewing the verbal narrative ad first triggers higher emotional values of excitement, both in the short and the long term, as well as frustration. It is also observed that having no experience with the product causes higher meditation values.
\end{abstract}


This can be useful to enterprises both in order to design their products in such a way as to orientate them towards consumer concerns, and to design advertisements in such a way as to link consumers emotionally with the product.

Keywords - advertising, usage scenarios, measured emotions, sustainable products, marketing research.

This study has been possible thanks to the research projects 151336.01/1 "El arte y el diseño en la nueva sociedad digital" funded by the Universitat Jaume I. The authors also wish to acknowledge the help of Sara Romero, María Agost, Laura Martínez and all the participants in the experiment.

\section{Introduction}

A wide range of products for many different functions are continually being replaced or surpassed by new products that come into being thanks to advances made in technology or the appearance of new needs. Sometimes a product is good for a specific use, but not so much so for a different use. This makes the user feel dissatisfied and left with the need to purchase more products than expected (Cooper, 2005). Within the context of sustainability, these patterns are related with eco-efficiency, which seeks to reduce the consumption of materials and energy, increase recyclability, and extend the life of the product (Verfaillie and Bidwell, 2000). The need to reduce the consumption of natural resources is highlighted by the number of products with a high percentage of recyclable or reusable materials that are currently thrown away (Pérez-Belis et al., 2012). Yet, the high costs and difficulties involved in recycling may turn out to be insurmountable obstacles for many countries in the future (World Business Council for Sustainable Development (WBCSD), 1995, 2000), and thus increasing the intensity of the service and the useful life of the product is a commitment to the future (Sundin et al., 2009).

In order to encourage the use of this kind of products it is important for the consumer to know and to be aware of the environmental and economic advantages they offer. 
Examples of products designed following these guidelines are convertible children's furniture or modular mobile phones, which allow components to be exchanged, thereby avoiding their full disposal.

In promoting these products only their functional (ease-of-use), aesthetic or quality aspects are normally depicted, with little attention paid to the different possibilities that can benefit the future consumer in terms of the possibilities of adapting them to different uses or their economic advantages, as they avoid the need to acquire new products.

The advertising of products that are respectful with the environment is based on their differentiation from conventional products, and can also be emotional (Schuhwerk and Lefkoff-hagius, 1995). Several studies have analysed the causes and consequences of emotions in consumers' behaviour (Watson and Spence, 2007), using techniques like eye-trackers and conductive bracelets (Guerreiro et al., 2015), as well as emotional recognition through expressions (Tombs et al., 2014). Knowing the consumers' emotional response can therefore provide data about their possible willingness to acquire products and their awareness about the advantages they offer.

The aim of this work is to determine whether there is a difference in perception between watching a commercial video (visual narrative) showing the functionality and use of a pushchair and an animated video (verbal narrative) that explains the problems and the advantages of using the new product by measuring the neuronal response of the possible users by means of an EEG headset. By so doing, the intention is to determine whether consumers accept new arguments for choosing a novel product based on new usage scenarios, and also whether the design of products and their ensuing advertising and promotion through a sustainable approach can generate a more positive emotional response in the future users of the product than with the application of traditional forms of promotion (visual narrative commercial ads). This study will take into account 
whether having previous experience with this kind of product affects how they are perceived, an important aspect when it comes to baby-care products. Another parameter that must be controlled for is the order in which the two videos are viewed, in order to determine whether this factor must be taken into account when it comes to deciding how the product and its message are to be shown.

\section{Theoretical background}

\subsection{Green advertising}

According to Kotler and Keller (2009) promotion involves "sales promotion, advertising, sales force, public relations and direct marketing". Advertising is an element of the marketing communication mix and can be defined as "any paid form of nonpersonal presentation and promotion of ideas, goods, or services by an identified sponsor".

Ann et al. (2012) add that consumers are more concerned about the promotion of ecological products if they think that the reason for preservation or slowing down environmental deterioration is worthwhile. Advertising is vital since it attracts the attention of consumers who are respectful with the environment. It can have an influence on consumers due to the emotive aspect that surrounds the action. Consequently, it can help highlight recognition of a product in the shop due to the characteristics that appeal to them (Morel and Kwakye, 2012).

Furthermore, there are studies that claim that consumers are sceptical about green advertising and often do not trust the ecological tactic, since they believe that it may be exaggerated (Chang, 2011; Rahbar and Wahid, 2011). Other authors are more specific, such as Wanninayake and Randiwela (2008), who consider that half of those surveyed claim that advertising has an influence on their decision to buy green products. Chase 
and Smith (1992) found that $70 \%$ of respondents may be influenced in order to buy ecological products "sometimes" but, as Rahbar and Wahid (2011) point out, not always, since consumers do not pay a great deal of attention to the messages due to their excessive use.

It may therefore be interesting to consider a new way of showing the environmental advantages that this kind of products offer by means of more emotive advertising with a powerful narrative that creates another kind of closer and more direct message.

\subsection{Attitudes and purchase behaviour}

From the psychological perspective, authors like Eagly and Chaiken (1993) define attitude as a tendency that is expressed by evaluating a particular entity with a degree of liking or displeasure. Salomon et al. (2010) analyse it from the perspective of consumers' behaviour, defining it as a durable and general evaluation of people (including themselves), objects or problems. The AMA defines it as the cognitive process that implies positive and negative valences, feelings or emotions (marketingpower.com).

According to Morel and Kawkye (2012) purchase intention can be defined as "what consumers think they are going to buy". Consumers' intentions play an important role in marketing strategy since they allow enterprises to evaluate how many products can be manufactured according to demand. In order to predict purchase intention and future behaviours, enterprises can interview consumers about their past behaviours and their intentions for the near future. With the information obtained they can estimate the probability of a particular behaviour. As Blackwell et al. (2006) point out, it is easier to predict intentions tomorrow than in a month, and easier in a month than in five years, since behaviour changes over time. It can therefore be said that knowing the acceptance of this type of product before it is launched on the market can be a competitive 
advantage.

\subsection{Evoked emotions and consumers}

Knowledge of the emotion process, that is, how emotions are evoked, can improve our understanding of what makes us enjoy interaction with any kind of product (Desmet, 2003). Users' needs and preferences are primary concerns in the development of products within a highly competitive market (Hsu et al., 2000). With the aim of satisfying consumers' needs, designers have to make the connotative and denotative meanings of their products explicit (Lin et al., 1996). It therefore comes as no surprise that consumer researchers have found that the emotions evoked by products enhance the pleasure of purchasing, owning and using them (Hirschman and Holbrook, 1982).

Within this context, several studies have focused on measuring costumers' emotions (de Hooge, 2014) and identifying and classifying the possible emotions that costumers can express with regard to brands (Romani et al., 2012). Among these studies, Pham et al. (2013) use questionnaires to evaluate the emotional response of costumers when they watch a TV commercial. The emotions taken into account in this study are included within the category "cognitive states" and belong to category 7 of the taxonomy developed by Storm and Storm (1987).

Nevertheless, it is still not clearly understood how consumers perceive a product form and how the meaning of the product form can be conveyed to them efficiently. This is due to the fact that users' feelings about the product make up a very complex cognitive process and many intricate factors contribute to the perception of a product form (Hsu et al., 2000).

Measuring the emotions experienced by the consumer on viewing an advertisement that shows the environmental advantages can therefore be a competitive advantage, as it eliminates the subjectivity of other methods such as questionnaires. 


\subsection{Usage scenarios in the conceptualisation of products}

The conceptualisation of products that have a prolonged useful life often uses the storytelling tool to obtain different usage scenarios, which are defined as explicit descriptions of hypothetical events related to a product during a specific phase of its life cycle (Anggreeni and van der Voort, 2007). The creation of scenarios is a technique for developing stories related to the use of the product and interaction with the consumer, in both present and future situations.

Suri and Marsh (2000) highlight the fact that the construction of scenarios gives the chance to explore and communicate qualitative aspects of the experience of the consumer at the beginning of the design process. Scenarios work as explicit descriptions of the hypothetical future of products and services (van der Bijl-Brouwer and van der Voort, 2013).

A great number of enterprises have become aware of the emotional value of stories (Lundqvist et al., 2013) and marketers use stories - either real or invented - in order to create an atmosphere with which to improve the uniqueness of a brand and its services (Mossberg and Nissen Johansen, 2006); consequently, they have increased the use of storytelling in marketing. They claim that stories are stored in memory in multiple forms: objectively, visually and emotionally. This therefore makes it very likely that consumers will remember it. Advertisements generated from stories increase the positive emotions, like optimistic or warm feelings (Escalas, 2004). The use of the stories/scenarios generated during the conception of the material for promoting/advertising these products can thus be a competitive advantage.

According to Lien and Chen (2013), by telling stories, narrative advertisements can communicate effectively by capturing consumers' attention to promote the advertised products, demonstrate the appeal of the products, and persuade consumers to consider 
those products (Escalas, 1998). Narrative ads represent one of the regular methods that advertisers use to explain the gains consumers can achieve by using their products (Woodside et al., 2008).

Some studies have already shown that narrative advertisements have a greater persuasive effect than non-narrative ones (Chang, 2008; Escalas, 2004; Mattila, 2000; Polyorat et al., 2007). Deighton et al. (1989) also note that the participants in this study respond to narrative advertisements with fewer counterarguments, which implies that the attitude towards the product increases in narrative advertisements to a greater extent than in those that are not narrative. According to Green and Brock (2002) narrative helps consumers to become immersed in the advertisements, thereby reducing negative responses and creating strong feelings about the characters. Moreover, when consumers find themselves before a visual narrative that uses vivid images to describe a story, they do not need to draw on their ability to create images and it therefore becomes easier to understand than in the case of verbal narrative (Lien and Chen, 2013).

Consumers construct a link between their own concepts and the products in the advertisement, and the use of narrative in the ad makes it easier for them to string the information together (Lien and Chen, 2013). So, the first hypothesis is:

H1. An ad with verbal narrative that shows new usage scenarios of a product that prolong its useful life generates a more positive emotional response than an ad with a visual narrative that only contains functional aspects of the use of the product (manoeuvrability, assembly, etc.) in the same consumer profile.

\subsection{The consumer's previous experience}

Little attention is usually paid to previous experience and its influence upon the consumer's perception. According to Van Der Wagen (1994) "individual customers have many different perceptions which are influenced by their education, upbringing, 
experience and many other factors".

Blythe (1997) defines this process as a cognitive mapping or construct of the imagination, where consumers analyse their behaviour before and after the purchase based on their previous experiences in order to generate an evaluation from them. Not all this information, however, comes from the world around them but instead from a series of factors such as subjectivity, categorisation, selection, expectations and previous learning or past experience.

O'Neill and Palmer (2003) analysed the related literature and found that consumers rarely make the decision to purchase without taking into account their beliefs, experiences or knowledge (Arora, 1982; Bloch and Richins, 1983; Sheth et al., 1991; Solomon, 1999). The use of previous knowledge and their experience help them to obtain a criterion when faced with a multitude of stimuli (Chisnall, 1975).

Previous knowledge is defined as the amount of experience and familiarity one has with a product (good or service) that helps to improve decision-making skills, thereby reducing the cognitive effort (Alba and Hutchinson, 1987). Familiarity is understood in the experiential sense and is defined as "the number of product-related experiences accumulated by the consumer".

Assael (1992) stated that consumers evaluate products and/or services through their past experiences, expectations and associations.

According to Kara et al. (2009) "the purchase and use of a product may evoke feeling, emotions, or provide a mean for a person's self-expression and identity formation (Aaker, 1998; Richins, 1994)”.

Accordingly, evaluations will be conducted to determine whether the consumer's having had previous experiences with the use of products or in situations similar to those in the advertisement affects the emotions that are generated. Consequently, the second hypothesis is: 
H2. Consumers' previous experience in the acquisition and use of the product triggers an emotional response on viewing ads which show new usage scenarios that convey a message related to their experience which differs from that of users without such experience.

\section{Method}

To test the above hypothesis, an experiment was performed in order to determine the emotive signals of the consumers, regarding their previous experience with the problem that the selected product seeks to solve (experienced vs. non-experienced consumers), and how the information is delivered to them (verbal vs. visual narrative).

\subsection{Consumer profile and sample}

As stated earlier, the product selected as a case study was a babies' pushchair that can be adapted to different usage scenarios. Initially the pushchair will allow just one baby to be carried, although, if the parents have had a second child within a short space of time, it can also hold two babies of different ages simultaneously.

In this experiment, two different population groups answered the survey:

- Group 1: made up of mothers and fathers who had a single child aged below 18 months (non-experienced consumers).

- Group 2: with mothers and fathers who had two children, with an age difference between them of less than 2 years, the elder one being no more than 5 or 6 years old, to avoid recruiting parents who are totally unaware of current trends in baby-care products (experienced consumers).

The reason why a variety of profiles were chosen was to determine whether the message shown in the videos is received in the same way by the two different groups: parents who have never had to deal with the problem of having to carry two young children, 
although it could still happen, and those who have had such an experience. This classification into experienced and non-experienced consumers was performed based on the difference between expectation and experience postulated by Ricoeur (1988) and previous studies highlighting the differences in the attitudes of consumers regarding their experience of using a product (Wogalter et al., 1991). The subjects were recruited from among the research and administration staff at the university where the experiment was conducted, by means of announcements posted in two nursery schools near the university. The sample consisted of 28 people for the population with just one child (group 1) and 26 people for the population with two children (group 2). Survey, interview and emotional data were collected between May and July 2014. The information from the survey and the interview was used to discern relevant data such as whether the costumers were aware of the latest baby-care products on the market and their knowledge and perceptions on the Bugaboo brand. This experiment was conducted in collaboration with the enterprise Baby Essentials, which is interested in knowing the emotions generated in the promotion of a new product before launching it on the market. In this case, the product selected was a pushchair.

\subsection{Promotional videos used}

The aim of the experiment was to measure the users' emotional response (cognitive state) while watching two videos, one of them created for the experiment using animation (video $\mathrm{M}$ ) and the other being a commercial video (video $\mathrm{Y}$ ). Video $\mathrm{M}$ presents verbal narrative, while video $\mathrm{Y}$ has visual narrative. With the first video (M) the aim was to show future users how a pushchair could be used for a longer time and how it could be adapted to different situations both in the present and in the future. The concept shown in the video is the result of a joint project carried out with the company Baby Essentials (https://vimeo.com/129596346). The video was created exclusively for 
the experiment to show the usage scenarios obtained from the design process. The second video $(\mathrm{Y})$ is a video advertising a product that is already on the market - the extensible pushchair Bugaboo Donkey (www.youtube.com/watch?v=hXUo1dCJH2A). Both videos show concepts sharing similar characteristics. However, whereas the commercial video shows a final product with real people and settings, video $\mathrm{M}$ shows an animation while an off-screen voice establishes direct communication with the viewer.

\subsection{Emotiv EPOC EEG headset}

This study focused on neuronal response, since, according to Choppin (2000), Bos (2006) and Nie et al. (2011) EEG signals can be used in the recognition of emotions. Indeed, EEG has been used in the research and medical fields for about 80 years (Hondrou and Caridakis, 2012). The use of EEG devices to detect the electrical activity of the brain, however, is becoming increasingly popular in other areas of research, as it does not require any kind of physical effort by the user (Harrison, 2013). One of the most interesting recent devices in this field is the Emotiv EPOC headset ((https://emotiv.com/epoc.php), which stands out for being lightweight and easy to fit while also offering the user a great deal of freedom of movement. The Emotiv EPOC device is placed on the user's head and allows the intensity of his or her brain waves to be measured via 14 s electrodes located over 10-20 international system positions AF3, F7, F3, FC5, T7, P7, O1, O2, P8, T8, FC6, F4, F8 and AF4 using two reference electrodes, as shown in Figure 1a. The sampling rate is $128 \mathrm{~Hz}$, the bandwidth is $0.2-$ $45 \mathrm{~Hz}$, and the digital notch filters are at $50 \mathrm{~Hz}$ and $60 \mathrm{~Hz}$. The signals captured by the headset are decoded by means of the company's private proprietary algorithms, which classify them into five different emotions and show the degree of intensity for each of them: Long- and short-term excitement, frustration, engagement/interest and meditation, 
which are called "cognitive states" and are included in the seventh category of the taxonomy developed by Storm and Storm (1987). These parameters are recorded in real time by means of the Affective suite, as shown in Figure $1 \mathrm{~b}$.
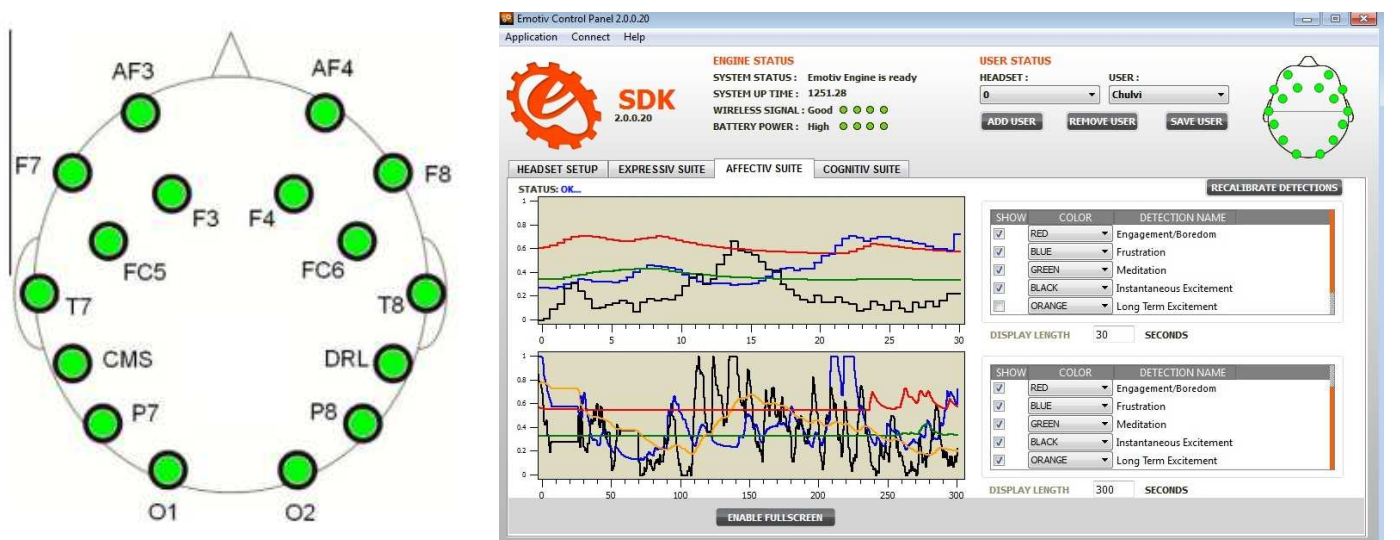

Figure 1. Positioning of the electrodes upon the scalp (Emotiv Epoc) (a). View of Afective Suite (b)

Emotiv has not publicly disclosed its classification algorithms, preferring to keep them as a trade secret. The model of emotion used in the EPOC device was constructed from data collected from over one hundred volunteers (Inventado et al., 2011). The validity of the data has been proved by studies conducted by Cernea et al. (2011), who presented a comparison between subjective emotions (questionnaires) and the measurements obtained using Emotiv EPOC headsets. The results of this study suggested that wireless EEG technology is capable of measuring subjectivity in the assessment of product and service satisfaction. Ekanayake (2010) confirmed the capacity of the Emotiv EPOC headset to pick up 'true' or 'real' EEG in an empirical study that evaluated the device on the basis of its capability to reflect the P300 component in an experimental study called the oddball paradigm. According to Duvinage et al. (2013), Emotiv EPOC headsets are undoubtedly an interesting option. Moreover, there is considerably more recent research that uses the Emotiv EPOC (Campbell et al., 2010, Khushaba et al., 2013, McMahan et al., 2015), and particularly its affective suit (Inventado et al., 2011; Pham and Tran, 2012; Ramirez and Vamvakousis, 2012; Fattouh et al., 2013; Chulvi and González- 
Cruz, 2016).

Nevertheless, previous studies have also found that the EPOC headsets have some shortcomings. One of the most important limitations involves the effect of accuracy in their measurements, which is reflected in false positives and negatives (Cernea, 2015). To solve this problem, Cernea (2015) proposed the introduction of prior training sessions. This training increases the rate of correct identification of facial and cognitive expressions by $12 \%$. Consequently, in this experiment a previous training phase by means of Cognitive Suite was included.

In our research, the intention is to capture direct information that is free of judgements about the subjects' reactions to the videos they are shown. The scope of the following research is not intended to be an exhaustive analysis of EEG signals processing, but to use the EEG tool and the software application elaborated by experts in order to obtain a wide collection of objective information for its subsequent analysis.

\subsection{Phases of the experiment}

The experiment was divided into phases, the first being reception of the subjects. Subjects were divided into groups of two individuals. This phase was performed outside the room where they were to watch the videos. The aim was to establish an atmosphere of trust and to relax anyone who came to the experiment in a stressed or worried state, so that the experiment would start under a set of calm (neutral) conditions. They were then introduced to the work team, the aims of the experiment were explained to them, they were offered food and drink (no stimulants) and lastly they were shown the Emotiv EPOC headsets that they were going to wear on their heads. In this same phase, the code of ethics for the experiment was explained to them and they were asked to sign a consent form. The duration of this phase was approximately 20 minutes. 
In the second phase, an EEG headset was placed on each subject's head and the sensors were checked to ensure all of them were showing the green light. Then, training was carried out by means of the Cognitive Suite in order to calibrate the equipment. Training lasted about ten minutes.

Lastly, the cognitive state was measured while viewing the videos (Figure 2). In this phase, the subjects watched the two videos, the commercial or visual one (Y) and the animated or verbal narrative one (M). At the end of each visualisation, subjects had to answer a brief perception test to provide them with some time to rest and "disconnect" between one video and the other (10 minutes approximately). Half the participants were asked to watch the commercial video first (YM order), while the other half viewed the animated one first (MY order). The videos were viewed on a 24" Led full-HD HDM screen at a distance of approximately $80 \mathrm{cms}$ in an isolated room lit with artificial light in order to prevent glare.

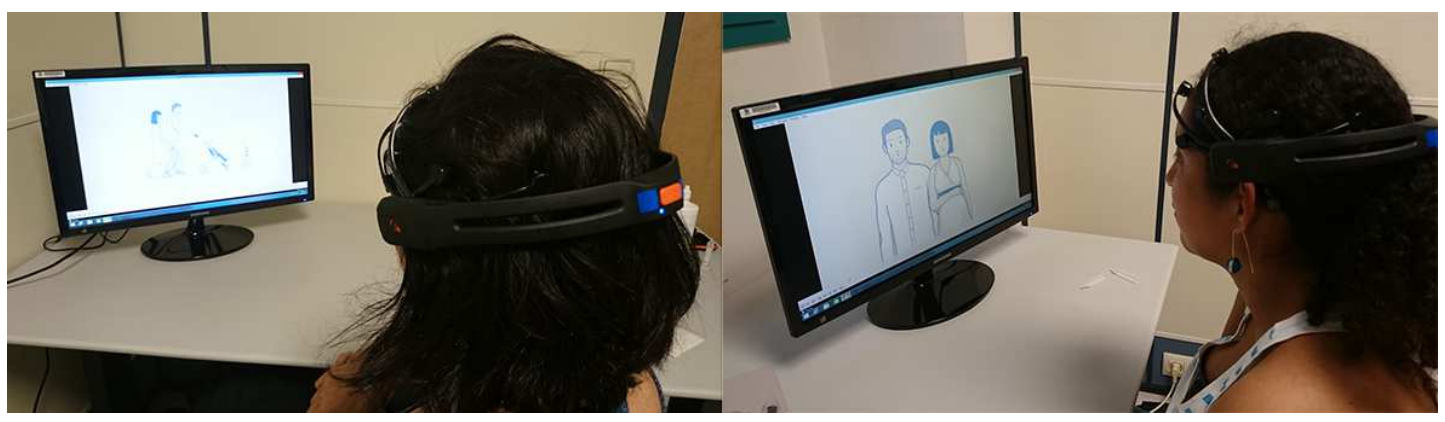

Figure 2. Measurement of perception while the animated video (M)

\subsection{Data treatment}

The outputs of the levels of intensity of the emotions were recorded in the range 0 to 1 to allow them to be processed statistically. Before performing the statistical analyses, the data obtained were filtered to test their validity. The conditions needed to detect the output values for the cases of signal loss or signal noise were reproduced experimentally. Within the set of data recorded for each user, the isolated measurements 
coinciding with these cases were counted and removed, the whole measurement being considered non-valid if the set of "non-valid" points reached a value of $15 \%$ of the total.

\section{Results}

As a result of the data treatment performed before the statistical analyses, only 40 of the 54 subjects initially selected were considered as valid. Table 1 shows the final number of men and women participating in the study as well as the group they belong to.

Table 1. Participants whose measurements by means of the EEG headset were accepted for the study

\begin{tabular}{|c|c|c|c|c|c|}
\hline & \multicolumn{2}{|c|}{ Non-experienced } & \multicolumn{2}{|c|}{ Experienced } & \multirow[t]{2}{*}{ TOTAL } \\
\hline & $M Y$ & $Y M$ & $M Y$ & $Y M$ & \\
\hline Females & 6 & 7 & 5 & 5 & 23 \\
\hline Males & 4 & 3 & 5 & 5 & 17 \\
\hline TOTAL & 10 & 10 & 10 & 10 & 40 \\
\hline
\end{tabular}

The mean values per user, group, video and viewing order, as well as their interactions, were studied for each of the parameters. Box and whisker plots were obtained for each variable in order to show the distribution of values and to distinguish the significant factors by means of ANOVA analyses.

As a step prior to the analysis of the averages, the data for each emotion were tested to determine whether they followed a normal distribution, validated with the KolmogorovSmirnov test with a critical Dn $(n=80$, alpha $=0.01)=0.182$, the following results being obtained for each emotion:

- ST Excitement: Dn $=0.142$

- LT Excitement: Dn $=0.153$

- Engagement: $\mathrm{Dn}=0.026$

- Meditation: $\mathrm{Dn}=0.178$

- Frustration: $\mathrm{Dn}=0.093$

The results obtained showed that all the variables measured with the headsets presented 
a normal distribution. Table 2 shows the average values of each video, group and viewing order as a whole, while in Table 2 they are shown separately according to the subgroups of possible combinations.

Table 2. Average of the intensity of each emotion per video, group and viewing order

\begin{tabular}{|l|llllll|}
\hline Emotions & Video M & Video Y & Group 1 & Group 2 & YM & MY \\
\hline ST Excitement & 0.2120 & 0.2248 & 0.1934 & 0.2434 & 0.1676 & 0.2691 \\
LT Excitement & 0.2408 & 0.2845 & 0.2497 & 0.2756 & 0.2306 & 0.2947 \\
Engagement & 0.6631 & 0.6614 & 0.6757 & 0.6489 & 0.6693 & 0.6552 \\
Meditation & 0.3526 & 0.3578 & 0.3740 & 0.3364 & 0.3682 & 0.3422 \\
Frustration & 0.4359 & 0.4611 & 0.4296 & 0.4674 & 0.4089 & 0.4881
\end{tabular}

Table 3. Average intensity of each population subgroup

\begin{tabular}{|c|c|c|c|c|c|c|c|c|}
\hline \multicolumn{5}{|c|}{ VIDEO Y } & \multicolumn{4}{|c|}{ VIDEO M } \\
\hline \multirow[b]{2}{*}{ Emotions } & \multicolumn{2}{|c|}{ GROUP 1} & \multicolumn{2}{|c|}{ GROUP 2} & \multicolumn{2}{|c|}{ GROUP 1} & \multicolumn{2}{|c|}{ GROUP 2} \\
\hline & YM & MY & YM & MY & YM & MY & YM & MY \\
\hline ST Excitement & 0.1370 & 0.2661 & 0.1767 & 0.3192 & 0.1689 & 0.2016 & 0.1878 & 0.2897 \\
\hline LT Excitement & 0.2619 & 0.2954 & 0.2243 & 0.3564 & 0.2363 & 0.2053 & 0.2000 & 0.3218 \\
\hline Engagement & 0.6980 & 0.6524 & 0.6660 & 0.6291 & 0.6784 & 0.6738 & 0.6348 & 0.6655 \\
\hline Meditation & 0.4010 & 0.3529 & 0.3522 & 0.3250 & 0.3817 & 0.3605 & 0.3379 & 0.3303 \\
\hline Frustration & 0.3893 & 0.4983 & 0.4076 & 0.5490 & 0.4163 & 0.4144 & 0.4222 & 0.4908 \\
\hline
\end{tabular}

Figure 3 displays the distribution of the average values for subjects' short-term excitement in box and whisker plots. This figure shows the separation by group (experienced or non-experienced users) and by video viewed (visual narrative or verbal narrative). The variable "viewing order" was added to the analysis, alternating the order in which the ads were viewed during the experiment being included in case this factor affects the results that are obtained. Moreover, separation by subgroup combining these three factors was considered. In the same way, Figure 4 shows the box and whisker plots for long-term excitement, and Figures 5, 6 and 7 the plots for engagement, meditation and frustration, respectively. 

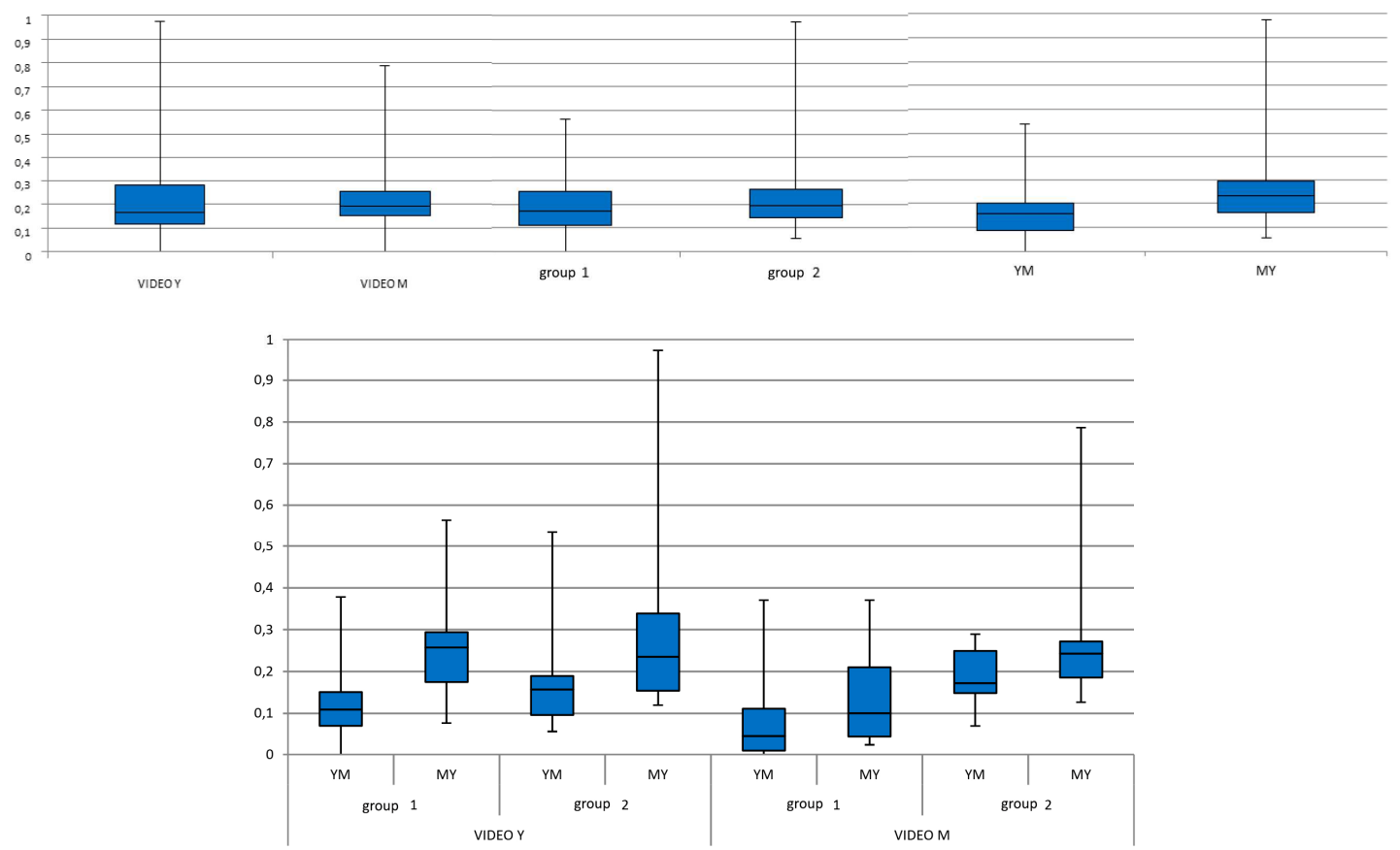

Figure 3. Box and whisker plot. Short-term excitement
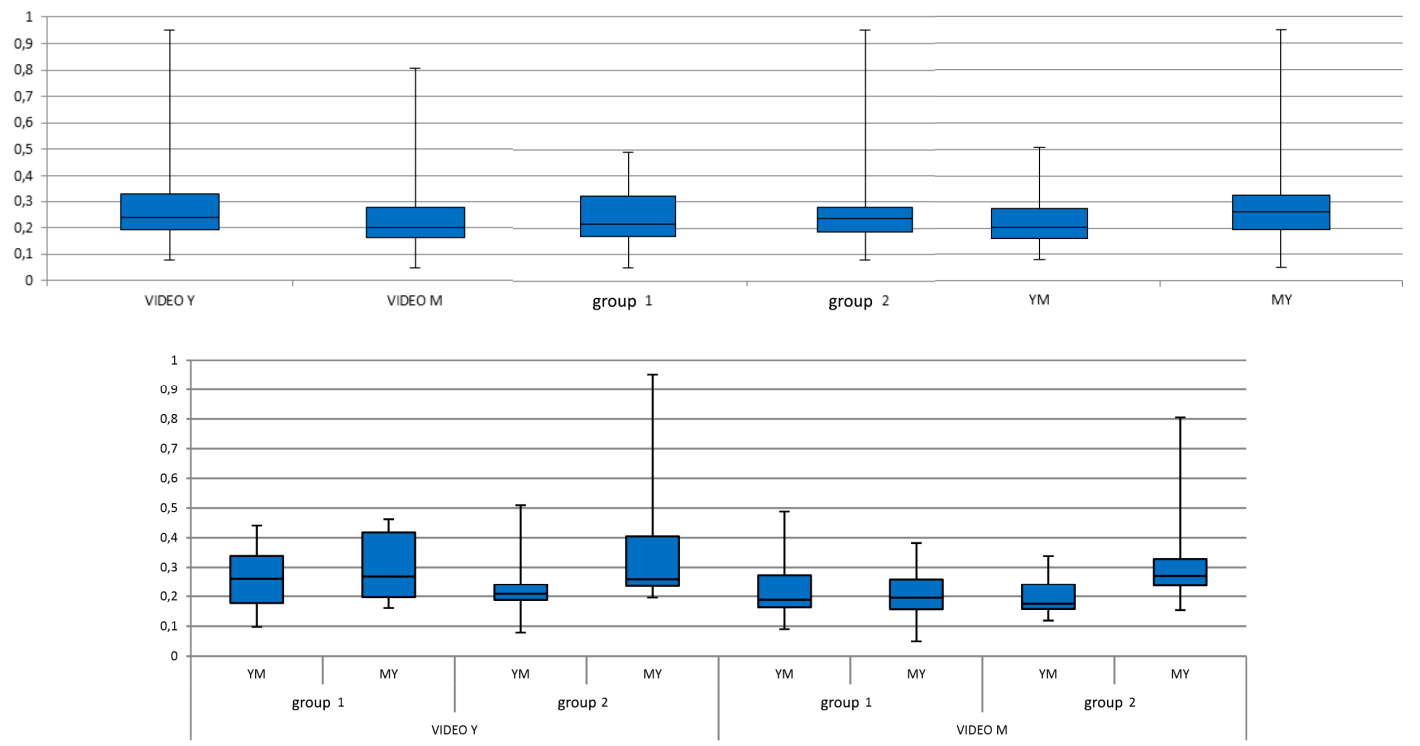

Figure 4. Box and whisker plot: Long-term excitement 

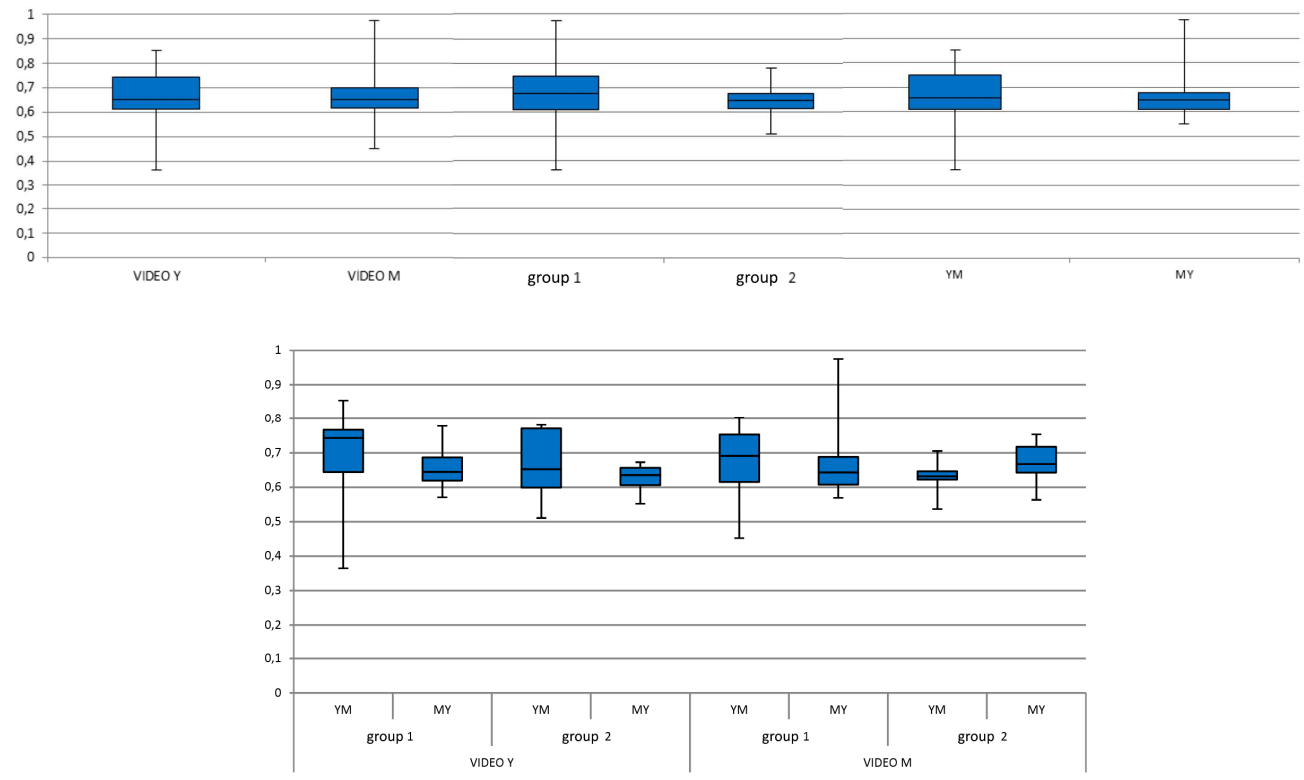

Figure 5. Box and whisker plot:Engagement
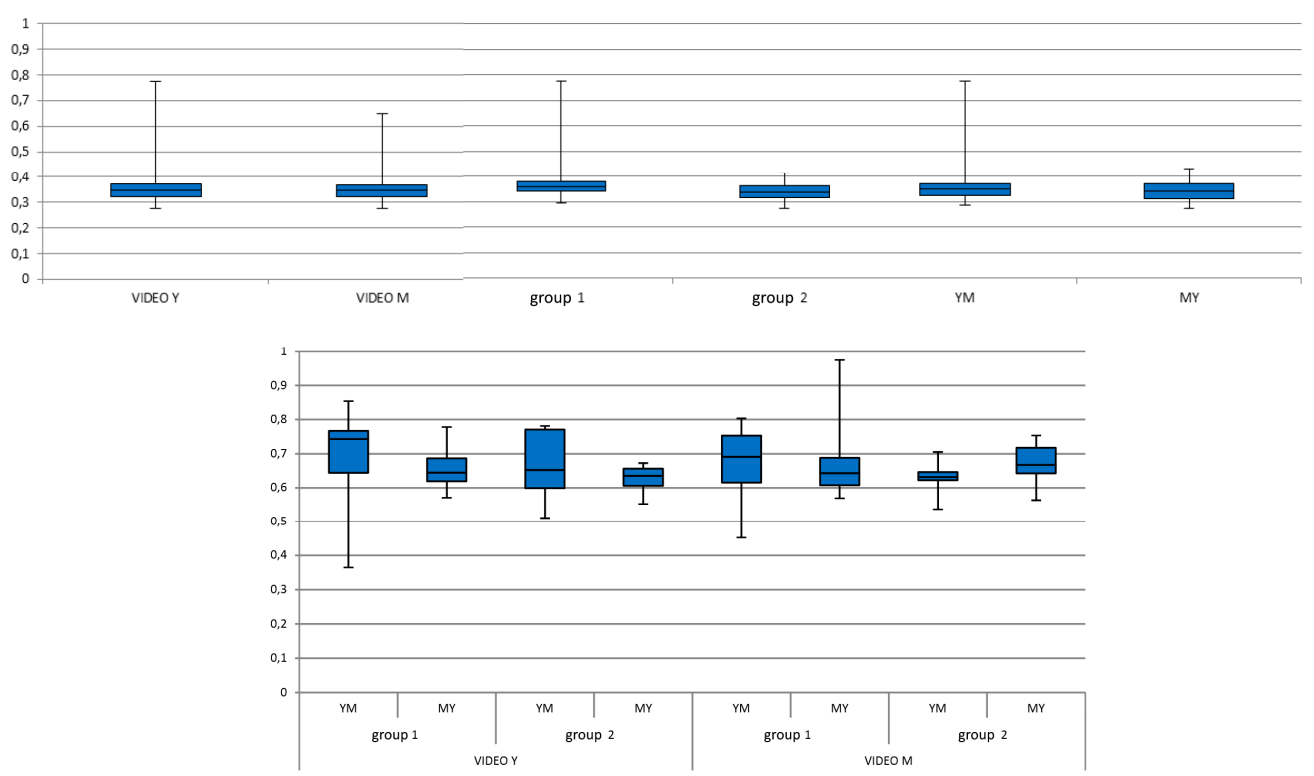

Figure 6. Box and whisker plot: Meditation 

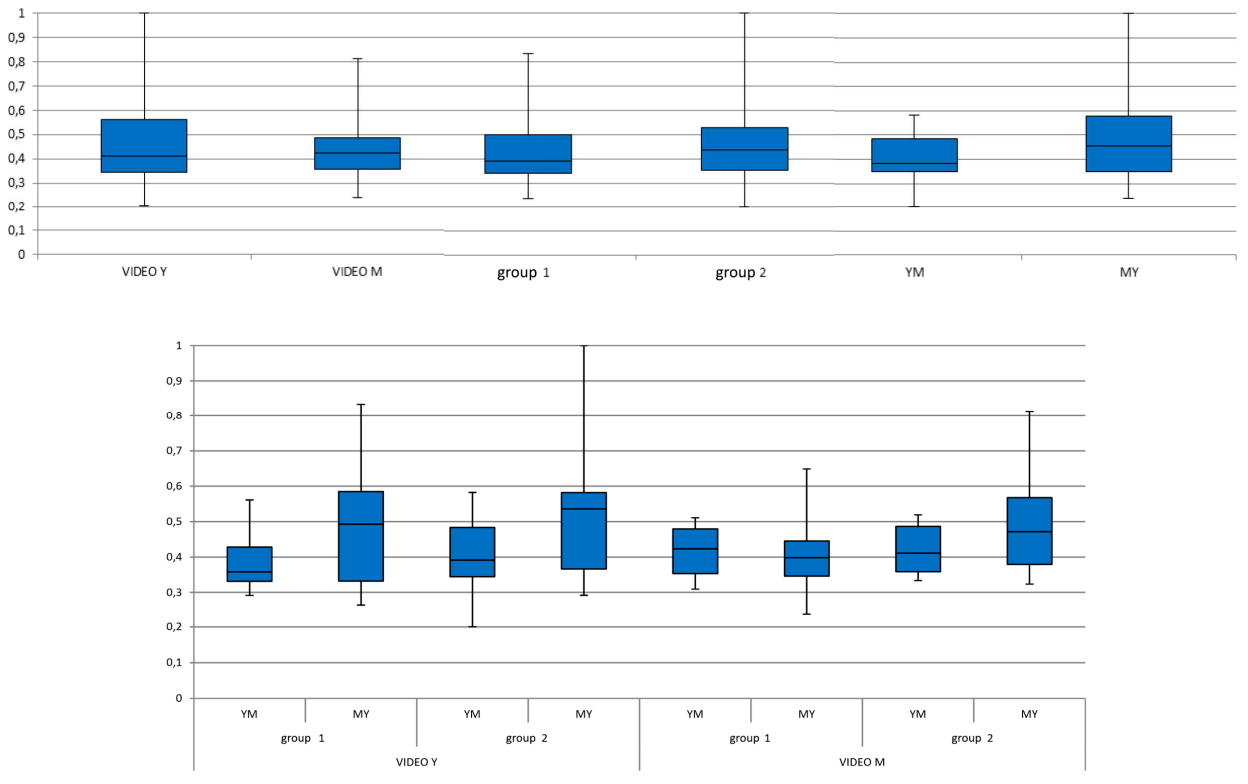

Figure 7. Box and whisker plot: Frustation

Likewise, several ANOVA analyses were performed with the aim of determining whether the possible differences found on separating the sample according to its variables were significant or not, or whether they present significant interactions. Table 4 shows the result of these analyses, those found to be significant being highlighted in bold.

"Table 4. ANOVA analyses of the different variables analysed.

\begin{tabular}{|c|c|c|c|}
\hline Emotions & Group & Video & Order \\
\hline \multirow{4}{*}{$\begin{array}{l}\text { ST Excitement } \\
\text { LT Excitement } \\
\text { Engagement } \\
\text { Meditation }\end{array}$} & $\mathrm{F}(1,78)=2.09 ; \mathrm{p}=0.152$ & $F(1,78)=0.13 ; p=0.715$ & $F(1,78)=8.91 ; p=0.004$ \\
\hline & $F(1,78)=0.65 ; p=0.422$ & $F(1,78)=1.86 ; p=0.175$ & $F(1,78)=4.16 ; p=0.044$ \\
\hline & $F(1,78)=1.77 ; p=0.187$ & $F(1,78)=0.01 ; p=0.932$ & $F(1,78)=0.62 ; p=0.434$ \\
\hline & $F(1,78)=6.63 ; p=0.012$ & $F(1,78)=0.12 ; p=0.733$ & $F(1,78)=3.04 ; p=0.085$ \\
\hline Frustration & $F(1,78)=1.37 ; p=0.246$ & $F(1,78)=0.60 ; p=0.442$ & $F(1,78)=6.38 ; p=0.013$ \\
\hline Emotions & Group-video interaction & Order-video interaction & Group-order interaction \\
\hline \multirow{5}{*}{$\begin{array}{l}\text { ST Excitement } \\
\text { LT Excitement } \\
\text { Engagement } \\
\text { Meditation } \\
\text { Frustration }\end{array}$} & $F(1,78)=0.01 ; p=0.919$ & $F(1,78)=1.06 ; p=0.306$ & $F(1,78)=0.39 ; p=0.532$ \\
\hline & $F(1,78)=0.19 ; p=0.660$ & $F(1,78)=0.35 ; p=0.533$ & $F(1,78)=4.13 ; p=0.045$ \\
\hline & $F(1,78)=0.00 ; p=0.968$ & $F(1,78)=1.78 ; p=0.185$ & $F(1,78)=0.61 ; p=0.434$ \\
\hline & $F(1,78)=0.00 ; p=0.964$ & $F(1,78)=1.78 ; p=0.185$ & $F(1,78)=0.29 ; p=0.589$ \\
\hline & $F(1,78)=0.01 ; p=0.920$ & $F(1,78)=2.16 ; p=0.145$ & $F(1,78)=0.68 ; p=0.414$ \\
\hline
\end{tabular}




\section{Discussion}

\subsection{Short-Term Excitement (STE)}

If we compare ST excitement in the videos that were viewed, in Figure 3 it can be seen that the median is slightly higher for the verbal narrative video, but the ANOVA analysis, however, shows that these differences are not significant. Neither were any significant differences found when comparing the variable of the population group, although in Figure 3 the median is seen to be slightly higher for group 2.

Nevertheless, the ANOVA analysis indicates that the differences in short-term excitement depending on the order in which the videos are viewed are significant. In this case we can see that the value of the median is higher when the verbal narrative video is watched first (MY), although it presents a higher dispersion of values. Therefore, we could claim that viewing the videos in the MY order triggers greater STE. This suggests that promoting these products by offering this kind of information in this order can have a greater impact on the user.

Regarding the different interactions among the variables, none of them has been seen to be significant.

\subsection{Long-Term Excitement (LTE)}

The graph in Figure 4, which corresponds to LT excitement, shows that the median is slightly higher for video $\mathrm{Y}$, but the ANOVA analysis reveals that this small variation is not significant. The same happens on comparing the variable "group", where the median is slightly higher for the experienced group, but is not significant either. Nonetheless, as occurred in the case of ST excitement, the ANOVA analysis showed that the variations in LT excitement measures in the viewing order are significant. In this case, as can be seen in Figure 4, the median of the values is higher when the narrative video is watched 
first (MY order). This viewing order also displays a higher dispersion of values in positive values. These results therefore indicate that it might be worth considering combining the two types of narrative, by including a first part consisting in a verbal narrative ad when it comes to promoting the product, with the aim of intensifying the consumer's level of excitement.

If we compare the interactions among the different variables, viewing order, group and video watched, the ANOVA analysis confirms that the interaction between the group and the viewing order is also a significant value, and the other two interactions are not. Hence, besides causing higher values of excitement when the verbal narrative video is watched first (MY), these values are reinforced if the viewer has some experience with the problem. This could be due to the fact that, with the verbal narrative at the beginning of the ad, the situation might be described better and this could cause customers who have experienced a similar situation to see themselves reflected in this situation, which is manifested in higher LT excitement values.

\subsection{Engagement}

If we compare the values obtained for the emotional parameter engagement in the videos, in Figure 5 it can be seen that the median is similar in both videos; the ANOVA analysis corroborates this similarity by indicating that the differences are not significant. With regard to the group, the median is slightly higher for group 1, the non-experienced subjects, but the ANOVA analysis shows that this difference is not significant. In the case of engagement, the viewing order has no significant influence on the levels that were measured, in accordance with the ANOVA analysis. In fact, the median values for viewing order are very similar in both cases. Moreover, the analysis of the interactions among the three variables shows that none of them present any significant differences. Consequently, we could claim that the engagement shown by consumers when watching 
an ad does not depend on the variables considered in this study.

\subsection{Meditation}

On comparing the values obtained with regard to the emotional parameter meditation in the videos that were watched (Figure 6), it can be observed that the median is similar in both videos. The ANOVA analysis confirms the similarity between the medians by indicating that there are no significant differences. Depending on the group, it can be confirmed that the median is higher for group 1. In this case, the ANOVA analysis shows that this data is significant. This therefore indicates that having no experience with the product/situation makes people think more deeply about what they are seeing. With regard to the influence of the order of visualisation of the videos on the users' meditation, similar median values were obtained. The ANOVA analysis confirms the similarity of the medians, since the difference is non-significant.

When the different interactions among the variables are compared, none of them were seen to be significant.

\subsection{Frustration}

If we compare the values obtained for frustration in the videos, in Figure 7 it can be seen that the median is slightly higher when viewing video M. According to the ANOVA analysis, however, this difference in the median is not sufficient for it to be considered significant. Neither was the difference found on analysing the data according to the group considered to be significant in the ANOVA analysis. In this case, the median for group 2 was perceived as slightly higher.

In contrast, the ANOVA analysis shows that there is a significant relation between frustration and the order in which the videos are watched. The highest median is obtained in this case when video $\mathrm{M}$ is viewed first. That is, the MY viewing order 
generates a higher values of frustration than the YM order. Analysing the repercussions of this result may be more complex because the same viewing order stimulates two different cognitive states at the same time: excitement and frustration. The consumer therefore presents a combination of emotions that must be interpreted. On the one hand, there is the increase in excitement, which is considered to be positive, and, on the other, the increase in frustration, which is considered negative. The authors think that, in fact, the emotion presented by the consumer can be another of those represented in the taxonomy of Storm and Storm (1987). This emotion results from the combination of the previous two but could not be measured directly due to the limitations of the equipment chosen to capture the EEG data, which only convert five predefined emotions. Therefore, taking into account the full taxonomy of emotions of Storm and Storm (see Figure 1 in their work), the authors suggest that the emotion resulting from the combination of frustration and excitement belongs to the category that contains the terms agitation, anxiety, nervousness and tension. A more comprehensive study will need to be conducted in order to test whether this new hypothesis is true, and to determine the causes that make viewing first the verbal part and then the visual part generate this supposed agitation or tension in the costumer.

Lastly, we performed a joint analysis of the three variables to be taken into consideration and their interactions: videos viewed, viewing order and population group. The study of the interactions among the three variables does not show any significant differences.

\section{Conclusions}

Regarding the main objective posited in this study, namely, to determine whether there is a difference in perception between watching a visual narrative ad showing the functionality and use of a pushchair and a verbal narrative ad that explains the problems 
and the advantages of using the new product, collecting EEG signals interpreted as emotional parameters included within those considered as cognitive states in the taxonomy of Storm and Storm (1987) shows that:

Hypothesis 1, "A verbal narrative ad that shows new usage scenarios of a product that prolong its useful life generates a more positive emotional response than an ad with a visual narrative that only contains functional aspects of the use of the product (manoeuvrability, assembly, etc.) in the same consumer profile", cannot be demonstrated, since there are no significant data to indicate that viewing a verbal narrative advertisement centred on showing the environmental advantages of a product by using emotional elements generates a more positive emotional response than a visual narrative ad in the same consumer profile.

Regarding Hypothesis 2, "Consumers' previous experience in the acquisition and use of the product triggers an emotional response on viewing adverts which show new usage scenarios that convey a message related to their experience which differ from that of users without such experience", it has been shown that the parents in group 1 obtained higher values for meditation than the parents in group 2 in both videos. This could be due to the fact that their lack of experience causes them to think more deeply about what they are seeing.

As a parallel conclusion observed due to the authors' intention to avoid a non-controlled variable (viewing order), it was observed that when the consumer is shown two types of advertisement, one with a verbal narrative that uses new arguments, such as environmental aspects, prolonged usage life and the savings it implies, and a visual narrative advertisement that shows only the product functionality, the emotional reaction depends on the viewing order. Results indicate that viewing the verbal narrative video first (order MY) triggers a higher level of short- and long-term excitement in both videos. This conclusion is useful from the point of view of making it possible to create 
promotional material that has a greater impact on the user. But the viewing order MY also triggers higher levels of frustration. The fact that the same factor affects different emotional parameters, apparently opposed in their positive-negative perception, gives rise to more questions than answers. The authors therefore consider it a limitation of the study caused by the tool selected for EEG data registration and conversion, and propose new hypotheses to be tested in future research: whether the combination of two measured emotions really results in a new non-measured emotion (excitement and frustration equal to agitation or tension), and why viewing first a verbal narrative ad and after that a visual narrative ad increases this supposed agitation or tension.

Future research could also be aimed at comparing whether the advertisements of "less emotive" products (not associated to a baby, such as childcare products) have a similar influence on the results. Moreover, this kind of studies can be implemented with other factors such as age, gender, social stratum, etc., identifying groups of consumers that are conditioned by diverse stimuli in different ways.

Another issue to be studied is the length of the two videos: in future research it would be interesting to compare videos of the same length in order to test whether this factor affects the emotions that are generated.

During the experiment a video produced by the enterprise Baby Essentials, which is a small Spanish company in the childcare sector, was also tested. The aim was to find out the acceptance of a product that extended its useful life before it was launched on the market. Results show a higher level of effectiveness for the combined advertisements, which show the green properties that recall the emotional link with the consumer in the first part, and the functional use of the real product in a second part. The use of the initial advertisement in the experiment in order to test the acceptation of the product by consumers through storytelling and new usage scenarios was useful for the enterprise in 
order to know whether the product was going to meet good acceptance on the market or whether, conversely, the product must be redesigned before being launched. 


\section{References}

Aaker, D.A. (1998), Strategic Marketing Management, New York, NY: John Wiley.

Alba, J.W., and Hutchinson, J. (1987), "Dimensions of consumer expertise", Journal of consumer research, Vol. 13 No. 4, pp. 411-454.

Anggreeni, I. and van der Voort, M.C. (2007), "Tracing the Scenarios in Scenario-Based Product Design: a study to support scenario generation", Design Principles and Practices: An International Journal, Vol. 2 No. 4, pp. 123-136.

Ann, K., Amir, G. and Luc, W. (2012), “Go Green! Should Environmental Messages Be So Assertive?", Journal of Marketing, Vol. 46, pp. 95-102.

Arora, R. (1982), "Validation of an SOR model for situation, enduring, and response components of involvement", Journal of Marketing Research, pp. 505-516.

Assael, H. (1992), Consumer behavior and marketing action, $4^{\mathrm{TH}}$ ED., wes-Kent Publishing, Boston, MA.

Blackwell, R.D., Miniard, P.W. and Engel J.F. (2006), Consumer Behavior, 10th edition. Mason: Thomson Higher Education.

Bloch, P.H. and Richins, M.L. (1983), “A theoretical model for the study of product importance perceptions", The Journal of Marketing, pp. 69-81.

Blythe, J. (1997), The essence of consumer behaviour, Prentice-Hall: London.

Bos, D.O. (2006), "EEG-based emotion recognition", The Influence of Visual and Auditory Stimuli, [Online]. Available: http://hmi.ewi.utwente.nl/verslagen/capitaselecta/CS-Oude BosDanny.pdf, pp. 1-17.

Campbell, A., Choudhury, T., Hu, S., Lu, H., Mukerjee, M.K., Rabbi, M. and Raizada, R.D.S.S. (2010), "NeuroPhone: Brain-Mobile Phone Interface using a Wireless 
EEG Headset", in Proceedings of the second ACM SIGCOMM workshop on Networking, systems, and applications on mobile handhelds - MobiHeld '10, New Delhi, India, pp. 3-8.

Cernea, D., Olech, P.S., Ebert, A. and Kerren, A. (2011), "EEG-based Measurement of Subjective Parameters in Evaluations", in International Conference on HumanComputer Interaction, Springer Berlin Heidelberg, pp. 279-283.

Cernea, D. (2015), User-Centered Collaborative Visualization, $\mathrm{PhD}$ Thesis, University of Kaiserslautern, Germany.

Chang, C. (2008), "Increasing mental health literacy via narrative advertising”, Journal of Health Communication, Vol. 13, pp. 37-55.

Chang, C. (2011), "Feeling ambivalent about going green-Implication for Green Advertising Processing", Journal of Advertising, Vol. 40 No. 4, pp. 19-31.

Chase, D. and Smith, T.K. (1992), "Consumers keen on green but marketers don't deliver", Advertising Age, Vol. 63 No. 29, pp. 2-4.

Chisnall, P. M. (1975), Marketing: a behavioural analysis, New York: McGraw Hill.

Choppin, A. (2000), "EEG-based human interface for disabled individuals: Emotion expression with neural networks", Master's thesis, Tokyo Institute of Technology, Yokohama, Japan.

Chulvi, V. and González-Cruz, M.C. (2016), "The influence of design methodology on a designer's emotional parameters and on design results", in Dyna Colombia, Vol. 83 No. 196, pp. 106-112.

Cooper, T. (2005), "Slower Consumption: Reflection on Product Life Spans and the “Throwaway Society””, Journal of Industrial Ecology, Vol. 9 No. 1-2, pp. 51-67. 
de Hooge, I.E. (2014), "Predicting consumer behaviour with two emotion appraisal dimensions: Emotion valence and agency in gift giving", International Journal of Research in Marketing, Vol. 31, pp. 380-391.

Deighton, J., Romer, D. and McQueen, J. (1989), "Using drama to persuade”, Journal of Consumer research, Vol. 16 No. 3, pp. 335-343.

Desmet, P. (2003), Measuring emotion: Development and application of an instrument to measure emotional responses to products, in Funology, Springer Netherlands.

Duvinage, M., Castermans, T., Petieau, M., Hoellinger, T., Cheron, G. and Dutoit, T. (2013), "Performance of the Emotiv Epoc headset for P300-based applications in BioMedical Engineering OnLine, Vol. 12 No. 1, pp. 1-13.

Eagly, A.H. and Chaiken, S. (1993), The Psychology of Attitudes, Fort Worth, TX: Harcourt Brace Jovanovich.

Ekanayake, H. (2010), "P300 and Emotiv EPOC: Does Emotiv EPOC capture real EEG?", available at: http://neurofeedback.visaduma.info/emotivresearch.htm (accessed 12 May 2017).

Emotive EPOC (2017), "Emotive EPOC", available at: https://emotiv.com/epoc.php (accessed 12 May 2017).

Escalas, J.E. (1998), “Advertising Narratives: What Are They and How Do They Work?" in Representing Consumers: Voices, Views, and Visions, Barbara Stern, ed., London: Routledge, pp. 267-289.

Escalas, J.E. (2004), "Imagine yourself in the product: Mental simulation, narrative transportation, and persuasion”, Journal of Advertising, Vol. 33 No. 2, pp. 37-48.

Fattouh, A., Horn, O. and Bourhis, G. (2013), "Emotional BCI Control of a Smart Wheelchair", International Journal of Computer Science Issues, Vol. 10 No. 3, pp. 
$32-36$.

Green, M.C. and Brock, T.C. (2002), "In the mind's eye: Transportation-imagery model of narrative persuasion", Narrative impact: Social and Cognitive Foundations. New York: Lawrence Erlbaum, pp. 315-341.

Guerreiro, J., Rita, P. and Trigueiros, D. (2015), “Attention, emotions and cause-related marketing effectiveness", European Journal of Marketing, Vol. 49 No. 11-12, pp. 1728-1750.

Harrison, T. (2013), “The Emotiv mind: Investigating the accuracy of the Emotiv EPOC in identifying emotions and its use in an Intelligent Tutoring System", $\mathrm{PhD}$ Thesis, Department of Computer Science and Software Engineering, University of Canterbury.

Hirschman, E.C. and Holbrook, M.B. (1982), "Hedonic consumption: Emerging concepts, methods and propositions", Journal of Marketing, Vol. 46, pp. 92-101.

Hondrou, C. and Caridakis, G. (2012), “Affective, Natural Interaction Using EEG: Sensors, Application and Future Directions", in Artificial Intelligence: Theories and Applications. Springer Berlin Heidelberg, Vol. 7297, pp. 331-338.

Hsu, S.H., Chuang, M.C. and Chang, C.C. (2000), “A semantic differential study of designers' and users' product form perception", International Journal of Industrial Ergonomics, Vol. 25, pp. 375-391.

Inventado, P.S., Legaspi, R., Suarez, M. and Numao, M. (2011), "Predicting student emotions resulting from appraisal of its feedback", in Research and Practice in Technology Enhanced Learning, Vol. 6 No.2, pp. 107-133.

Kara, A., Rojas-Méndez, J.I., Kucukemiroglu, O., and Harcar, T. (2009), “Consumer preferences of store brands: Role of prior experiences and value consciousness. 
Journal of Targeting”, Measurement and Analysis for Marketing, Vol. 17 No. 2, pp. $127-137$.

Kotler, P. and Keller, K.L. (2009), Marketing Management, 13th edition, New Jersey: Pearson/Prentice-Hall.

Khushaba, R.N., Wise, C., Kodagoda, S., Louviere, J., Kahn, B.E., and Townsend, C. (2013), "Consumer neuroscience: Assessing the brain response to marketing stimuli using electroencephalogram (EEG) and eye tracking”, Expert Systems with Applications, Vol. 40 No. 9, pp. 3803-3812.

Lien, N.H. and Chen, Y.L. (2013), "Narrative ads: The effect of argument strength and story format", Journal of Business Research, Vol. 66 No. 4, pp. 516-522.

Lin, R., Lin, C.Y., and Wong, J. (1996), “An application of multidimensional scaling in product semantics", International Journal of Industrial Ergonomics, Vol. 18, pp. 193-204.

Lundqvist, A., Liljander, V., Gummerus, J. and Van Riel, A. (2013), “The impact of storytelling on the consumer brand experience: The case of a firm-originated story", Journal of Brand Management, Vol. 20 No. 4, pp. 283-297.

Mattila, A.S. (2000), "The roe of narratives in the advertising of experiential services", Journal of Service Research, Vol. 3 No. 1, pp. 35-45.

McMahan, T., Parberry, I. and Parsons. T.D. (2015),"Evaluating player task engagement and arousal using electroencephalography", Procedia Manufacturing, Vol. 3, pp. 2303-2310.

Morel, M. and Kwakye, F. (2012), “Green marketing: Consumers' Attitude towards Eco-friendly Products and Purchase Intention in the Fast Moving Consumer Goods (FMCG) sector”, PhD Thesis, Umeå School of Business, Sweden. 
Mossberg, L. and Nissen Johansen, E. (2006), Storytelling: Marknadsf $\ddot{o}$ ring $i$ upplevelseindustrin, [Storytelling: Marketing in the Experience Industry]. Göteborg, Sweden: Studentlitteratur.

Nie, D., Wang, X.W., Shi, L.C. and Lu, B.L. (2011), "EEG-based Emotion Recognition during Watching Movies", in The 5th International IEEE EMBS Conference on Neural Engineering, Cancun, Mexico, pp. 667-670.

O’Neill, M. and Palmer, A. (2003), “An exploratory study of the effects of experience on consumer perceptions of the service quality construct", Managing Service Quality: An International Journal, Vol. 13 No. 3, pp. 187-196.

Pham, T.D. and Tran, D. (2012), "Emotion Recognition Using the Emotiv EPOC Device”, in International Conference on Neural Information Processing, Springer Berlin Heidelberg, pp. 394-399.

Pham, T.M., Geuens, M. and Pelsmacker, D.P. (2013), “The influence of ad-evoked feelings on brand evaluations: Empirical generalizations from consumer responses to more than 1000 TV commercials", International Journal of Research in Marketing, Vol. 30 No. 4, pp. 383-394.

Pérez-Belis, V., Bovea, M.D., Gómez, A. and Ruiz, A. (2012), “Caracterización de residuos de aparatos eléctricos y electrónicos en su categoría 7 (juguetes)", in XVI International Congress On Project Management and Engineering, Valencia, Spain, pp. 973-984.

Polyorat, K., Alden, D.L. and Kim, E.S. (2007), "Impact of narrative versus factual print ad copy on product evaluation: The mediating role of ad message involvement", Psychology \& Marketing, Vol. 24 No. 6, pp. 539-554.

Ramirez, R. and Vamvakousis, Z. (2012), “Detecting emotion from EEG signals using 
the emotive epoc device", in International Conference on Brain Informatics, Springer Berlin Heidelberg, pp. 175-184.

Rahbar E. and Wahid N.A. (2011), "Investigation of green marketing tools' effect on consumers' purchase behavior", Business Strategy Series, Vol. 12 No. 2, pp. 73-83.

Richins, M.L. (1994), "Valuing things: The public and private meanings of possessions", Journal of consumer research, Vol. 21 No. 3, pp. 504-521.

Ricoeur, P. (1988), Time and narrative, Vol. 3. University of Chicago P. (University.). Chicago, IL.

Romani, S., Grappi, S. and Dalli, D. (2012), "Emotions that drive consumers away from brands: Measuring negative emotions toward brands and their behavioural effects", International Journal of Research in Marketing, Vol. 29 No. 1, pp. 55-67.

Sheth, J.N., Newman, B.I. and Gross, B.L. (1991), "Why we buy what we buy: A theory of consumption values", Journal of business research, Vol. 22 No. 2, pp. 159-170.

Schuhwerk, M.E. and Lefkoff-Hagius, R. (1995), “Green or Non-Green? Does Type of Appeal Matter when Advertising a Green Product?", Journal of Advertising, Vol. 24 No. 2, pp. 45-54.

Solomon, M.R. (1999), Consumer behaviour, $4^{\text {th }}$ ed., Prentice-Hall, Englewood Cliffs, NJ.

Solomon, M.R., Bamossy, G., Askegaard, S. and Hogg, M.K. (2010), Consumer Behaviour: A European Perspective, 4th edition. New York: Prentice Hall.

Storm, C. and Storm, T. (1987), "A taxonomic study of the vocabulary of emotions", Journal of personality and social psychology, Vol. 53 No. 4, pp. 805-816.

Sundin, E., Lindahl, M. and Ijomah, W. (2009), "Product design for product/service 
systems: Design experiences from Swedish industry", Journal of Manufacturing Technology Management, Vol. 20 No. 5, pp. 723-753.

Suri, J.F. and Marsh, M. (2000), "Scenario building as an ergonomics method in consumer product design”, Applied Ergonomics, Vol. 31 No. 2, pp. 151-157.

Tombs, A.G., Russell-Bennett, R. and Ashkanasy, M.N. (2014), "Recognising emotional expressions of complaining customers: A cross-cultural study", European Journal of Marketing, Vol. 48 No. 7-8, pp. 1354-1374.

van der Bijl-Brouwer, M., and van der Voort, M.C. (2013), "Exploring future use: scenario based design", in de Bont, C., Smulders, F.E., van der Voort, M.C., Schifferstein, R., and den Ouden, E. (eds.), Advanced design methods for successful innovation - Recent methods from design research and design consultancy in the Netherlands, Delft: Design United, pp. 57-77.

Van Der Wagen, L. (1994), Building quality service with competency based human resource management, Oxford: Butterworth Heinemann.

Verfaillie, H.A. and Bidwell, R. (2000), Eco-efficiency: a Guide To Reporting Company Performance, in World Business Council for Sustainable Development: Geneva.

Wannimayake, W.M.C.B. and Randiwela, P. (2008), "Consumer attractiveness towards Green Products of FMCG sector: An empirical study", Oxford Business and Economics Conference Program, pp. 1-19.

Watson, L. and Spence, M.T. (2007), "Causes and consequences of emotions on consumer behaviour: A review and integrative cognitive appraisal theory", European Journal of Marketing, Vol. 41 No. 5-6, pp. 487-511.

WBCSD (1995), "Eco-efficient leadership for improved economic and environmental performance", World Business Council for Sustainable Development, Geneva. 
WBCSD (2000), "Eco-efficiency: creating more value with less impact", World Business Council for Sustainable Development, Geneva.

Wogalter, M.S., Brelsford, J.W., Desaulniers, D.R. and Laughery, K.R. (1991), "Consumer product warnings the role of hazard perception", Journal of Safety Research, Vol. 22, pp. 71-82.

Woodside, A.G., Sood, S. and Miller, K.E. (2008), "When consumers and brands talk: Storytelling theory and research in psychology and marketing”, Psychology \& Marketing, Vol. 25 No. 2, pp. 97-145. 